\title{
ULAKBİM TR-Dizinde Taranan Eğitim Dergilerinde COVİ-19 Salgınıyla İlgili Makalelerin İncelenmesi
}

\section{Gürol ZIRHLIOĞLU* ve Şehnaz Nigar ÇELİK**}

Öz: Covid-19 salgını tüm dünyayı etkisi altına alan bir süreci de beraberinde getirmiştir. Şüphe yok ki bu süreç tüm bilim alanlarını olduğu gibi eğitim alanını da pek çok yönden etkilemiştir. Bu bağlamda düşünüldüğünde salgın sürecinin eğitim ile ilgili bilimsel çalışmalara da yansıyacağının kaçınılmaz olduğu söylenebilir. Bu çalışmayla salgın döneminde Covid-19 ile ilgili yapılan eğitim çalışmalarının hem konu eğilimleri bakımından hem de metodolojik olarak, nasıl bir yön aldığı konusunda fikir edinebilmek amaçlanmıştır. Çalışmada TR-Dizin resmi internet sayfasında veri tabanı olarak "sosyal" ve konu alanı olarak ise "eğitim, eğitim araştırmaları" filtrelemeleri sonucunda elde edilmiş olan 140 dergi incelenerek konu ile ilgili olarak, 2020 - 2021 (Nisan ayına kadar) yapılan 77 araştırma makalesinin yayımlandığı dergiler, yayınlandı̆̆ı yıl, yazar sayısı, konu eğilimi, örneklem yöntemi, hedef kitle, araştırmanın türü, araştırmanın modeli, veri toplama araçları, veri analiz yöntemlerinin nasıl dağılım gösterdikleri belirlenmeye çalışılmıştır. Yapılan çalışma nitel bir araştırma olup, doküman incelemesi yapılmış ve içerik analizi yöntemi kullanılmıştır. Çalışmada incelenen makalelerin çoğunlukla "uzaktan eğitime ilişkin görüş ve değerlendirme” ve "ders ve etkinlik değerlendirme" konularını ele aldıkları belirlenmiştir. Ayrıca, çalışmaların hedef kitlesinin genelde öğrenciler ve öğretmenler olduğu elde edilen bulgulardan bazılarıdır. Bu çalışma salgın sürecinin başlangıcından itibaren yaklaşık 13 aylık bir süreci kapsamaktadır. Salgının etkisinin azalması ile birlikte bu konu ile ilgili olarak eğitim alanındaki çalışmaların da artacağı düşünülmektedir.

Anahtar kelimeler: Covid-19, pandemi, eğitim, uzaktan eğitim

\footnotetext{
*Van Yüzüncü Yıl Üniversitesi, Eğitim Fakültesi, Ölçme ve Değerlendirme Ana Bilim Dalı, Orcid ID: 00000001-8687-1349, Email:gurolyyu@gmail.com

**Van Yüzüncü Yıl Üniversitesi, Eğitim Fakültesi, Eğitimin Felsefi, Sosyolojik ve Tarihi Alanları Ana Bilim Dalı, Orcid ID: 0000-0001-9949-0668,Email: sncelik@yyu.edu.tr
} 


\title{
The Examination of Articles Related to the COVID-19 Outbreak in Education Journals Indexed in ULAKBIM National Database
}

\begin{abstract}
The Covid-19 pandemic has brought with it a process that has affected the whole world. There is no doubt that this process has affected all fields of science as well as education in many ways. Considering within this context, it can be uttered that it is inevitable that the epidemic process will affect the scientific studies related to education. With this study, it is aimed to give an opinion on the direction of the educational studies on Covid-19 during the epidemic period, both in terms of subject trends and methodologically. In the study, 140 journals which were obtained as a result of filtering "social" as a database and "education, education research" as a subject area on the ULAKBIM National Index's official website were examined and 77 research articles published in 2020 - 2021 (until April) were found. It was tried to determine these 77 articles' publication year, the number of authors, the trend of the subjects, the sampling methods, the target audiences, the type of the researches, the models of the researches, the data collection tools, and how these data analysis methods varied. The study is a qualitative research. Document analysis was conducted and content analysis method was used. It has been determined that the articles examined in the study mostly deal with the subjects of "views and evaluation of distance education" and "course and activity evaluation". Furthermore, some of the findings are that the target audience of the studies is generally students and teachers. This study covers a period of approximately 13 months from the beginning of the epidemic process. It is thought that with the decrease of the effect of the epidemic, studies in the field of education will increase.
\end{abstract}

Keywords: Covid-19, pandemic, education, distance education 


\section{Giriş}

Bilimsel bulguların paylaşılmasında ve yayılmasında büyük bir öneme ve yere sahip olan bilimsel dergiler, bu türden incelemelerin yapılabilmesi için araştırmacılara geniş olanaklar sunmaktadır. Ayrıca dergilerde yayınlanan makalelerin yine günümüzde büyük bir çoğunluğunun elektronik ortamlarda yer alması ve açık erişim imkanına sahip olması bilimsel bilginin erişilebilir olmasına büyük imkanlar sağlamaktadır. Nitekim, Köksoy (2000), bilimsel araştırmaların sonuçlarının paylaşımının bilimsel dergilerin görevi olduğunu belirtir (Aktaran: Alemdağ, 2018). Dolayısıyla bilimsel dergiler, dünyanın neresinde olursa olsun, pek çok araştırmacıya yapılan bilimsel çalışmaları inceleme imkânı verir. Bu da beraberinde başka bir araştırma konusunu ortaya çıkartır: bilimsel çalışmaları incelemek.

Bir araştırma konusu olarak, herhangi bir konuyla ilgili yapılan bilimsel çalışmaların incelenmesine sıklıkla rastlamak mümkündür. Zira bu çalışmalar bir yandan konu ile ilgili yapılan çalışmaların niteliği ve alanda yapılan çalışmalar hakkında bilgi verirken (Seferoğlu ve Kurtoğlu, 2013, s.1) öte yandan başka araştırmacılara derli toplu bilgiler vermesi bakımından önem arz etmektedir. Özellikle belirli dönemlerde belirli konularda yapılan bilimsel çalışmaların yönelimlerinin neler olduğu konusunda da araştırmacılara önemli ölçüde 1şık tutmaktadır. Bilimsel makalelerin incelenmesi konusunda ülkemizde yapılan farklı konularda çalışmalarla karşılaşmak mümkündür. Yapılan çalışmalar incelendiğinde çalışmalarda makalelerin üniversitelere, dergilere, yıllara, araştırma konularına, yazar sayısına, katılımcı üniversite sayılarına, unvanlara, yazarların cinsiyetlerine göre dağılımlarının yanı sıra araştırmanın aşamalarına göre, başka bir deyişle araştırmanın yöntemine, örnekleme tekniğine göre, çalışma gruplarına göre, veri toplama araçlarına göre dağılımlarının incelendiği görülmektedir.

Kurtoğlu ve Seferoğlu (2013), öğretmenlerin teknolojiyi kullanmaları ilgili olarak Türkiye kaynaklı 33 dergide 2008-2013 yılları arasında yapılmış olan çalışmaları incelemiş ve inceledikleri makalelerin hangi dergilerde yayınlandığını, makalelerin yıllara göre dağılımlarının nasıl olduğu, araştırılan konuların eğilimlerinin ne olduğu ve kullanılan yöntem ile ilgili olarak genel bir değerlendirme ortaya koymuşlardır. Şara, Karadedeli ve Hasanoğlu (2016) sınıf yönetimi ile ilgili 2010-2015 y1lları arasında yazılan 59 makaleyi inceleyerek makalelerin yıllara, üniversitelere, katılımcı üniversite sayısına, dergilere, yazarların sayısına, unvanlarına ve cinsiyetlerine, illere, konulara ve yöntem içeriklerine göre dağılımlarının ne olduğu ile ilgili bir değerlendirme yapmışlardır. Alemdağ (2018), spor bilimleri alanıyla ilgili 
yapmış olduğu çalışmasında 2013-2017 yılları arasında makaleleri inceleyerek spor bilimleri alanındaki makalelerin yıllara göre dağılımını ve makalelerin spor bilimleri alanlarına göre dağılımını incelemiştir. Şahin ve Öztürk (2018), çalışmalarında ölçek geliştirme süreci ile ilgili olarak 2010-2016 yılları arasında yapılan 72 çalışmayı incelemişlerdir. Söz konusu bu çalışmalarında ölçek geliştirme süreci ile ilgili genel olarak, makalelerin yayınlandığı dergiler ile ilgili bilgilere, makalelerin giriş bölümü ile ilgili bilgilere, madde havuzunun oluşturulması, geliştirilen form, deneme uygulamalarındaki örneklem büyüklüğü ve uygulanan analizlerle ilgili bilgilere yer vermişlerdir. Doğan ve Tok (2018), eğitim bilimleri alanında yayınlanan 181 makaleyi "eğitim ve bilim dergisi” özelinde incelemişlerdir. Çalışmalarında makalelerin eğitim biliminin alt disiplinlere, konu alanlarına, araştırma modeline, örneklem kitlelerine, veri toplama yöntemlerine, veri analiz yöntemlerine, yazar sayısına ve yazarların bağlı olduğu kuruma ve akademik unvanlarına göre dağılımını incelemişlerdir. Çiftçi ve Ersoy (2019), çalışmalarında 2006-2007 yılları arasında okul öncesi eğitimine yönelik yapılan 250 çalışmayı ele alarak değerlendirmişlerdir. Araştırmacılar makalelerin kimliği ve künyesi hakkında bilgi vermenin yanı sıra yine yöntem, örneklem, veri toplama aracı ile ilgili olarak metodoloji bakımından da değerlendirmesini yapmışlardır. Benzer bir şekilde Hıdıroğlu ve Tanrı̈ğen (2020) öğretmen güçlendirme konusuyla ilgili olarak 2000-2019 yılları arasında yapılan 19 tez ve 51 makaleyi geniş bir değişken yelpazesinde incelemişlerdir. Yine Hıdıroğlu (2020) yaptığ bir çalışmasında 2013-2019 yılları arasında eğitim denetimi alanında yapılan 61 çalışmayı inceleyerek makalelerin yıllara, yazarların çalıştıkları kurumlara, yayın diline, yazar sayısına, örneklem grubuna, yöntemlerine, konularına, araştırmanın türüne, örneklem büyülüğüne, veri toplama ve analiz yöntemine göre dağılımlarını incelemişlerdir.

Literatürde bilimsel çalışmaların incelenmesi ile ilgili yapılan daha fazla sayıda çalışmaya rastlamak mümkündür. Ancak bu tip çalışmalarda ağırlıklı olarak göze çarpan şey yapılan çalışmaların belirli bir konu dahilinde, söz gelimi teknoloji kullanımı, ölçek geliştirme, sınıf yönetimi vb. konularda yapıldığıdır. Covid-19 ya da tüm dünyayı etkisi altına alan ve bütün dünyadaki eğitim şeklini bir anda değiştiren başka bir olayla ilgili olarak yapılan bu türden bir çalışmaya, mevcut imkanlar dahilinde, alan yazında rastlanamamıştır.

Bilindiği gibi, Dünya 2019 yılının Aralık ayında Çin’in Hubei eyaletinin Vuhan kentinde başlayan büyük bir salgın tehlikesiyle yüzleşmek zorunda kalmıştır. Bu tehlikenin etkileri 2020 yılının başından itibaren giderek bütün dünyayı sararak adeta insanlığı esareti altına almıştır. Dünya bir yılı aşkın bir süredir SARS-CoV-2 şeklinde tanımlanan ve klinik tablosu Coronavirus hastalığı COVİD-19 adını alan (Üstün ve Özçiftçi, 2020, s.143) ölümcül 
bir virüs ile mücadele içindedir. Maske-mesafe-temizlik, tüm insanlığın yeni mottosu haline gelmiştir. Bu durum, aslında insan yaşamında ne kadar süreceği tahmin dahi edilemeyen, bir değişimin de başlangıcı olmuştur. Salgın bir anda tüm insanların yaşam alışkanlıklarını değiştirmiş, sosyal ilişkilerde çeşitli önlemlerin alınmasının gerekliliğini ve zorunluluğunu doğurmuştur. Virüsün etkilediği alanların en önemlilerinden biri de hiç kuşkusuz ki eğitimöğretim uygulamaları olmuştur. Tüm dünyada her türden eğitime kısa süreliğine de olsa ara verilmiş ve nihayetinde örgün eğitime bir alternatif olarak, teknolojinin de avantajlarından yararlanılıp, uzaktan eğitim ile eğitim-öğretim devam ettirilmeye çalışılmıştır.

Covid-19 salgınının insan yaşamındaki etkilerini bilim insanlarının söylemlerinden, etrafımızda duyduklarımızdan, TV programlarından, kamu spotlarından ya da reklamlardan görebilmek mümkündür. Salgının pek çok bilimsel alanda yapılan çalışmalara da yansımasının kaçınılmaz olduğu düşünülmektedir. Şüphesiz ki bu alanlardan biri de eğitimdir. Eğitim alanında yapılan çalışmaların çoğunlukla eğitimin paydaşları ile ilgili olduğu ve yine çalışmaların büyük çoğunluğunun sahada yürütülen çalışmalar olduğu düşünüldüğünde, salgın sürecinin eğitimle ilgili yapılacak olan çalışmalara da yansıyacağı düşünülebilir. Bu bağlamda değerlendirildiğinde yapılacak olan bu çalışmanın önemi salgın döneminde Covid-19 ile ilgili yapılan eğitim çalışmalarının hem konu eğilimleri bakımından hem de metodolojik olarak, nasıl bir yön aldığı konusunda bir fikir edinebilmektir. Öte yandan salgın döneminde Covid-19 ile ilgili eğitim alanında yapılan çalışmaların tarama ve analiz çalışmaları ile ortaya konulmasının eğitim alanında çalışan araştırmacılar açısından yararlı olacağı da düşünülmektedir. Dolayısıyla bu çalışmanın amacı bu süreç içerisinde yapılan çalışmaların niteliği ya da niceliği değil, konu ve metodolojik yönelimlerinin ne olduğu ve salgın dönemi içerisinde eğitim alanında Covid-19 ile ilgili yapılan çalışmalar hakkında bilgi edinebilmektir. Bunun için aşağıdaki soruların cevabı aranmıştır:

ULAKBIM TR-Dizinde taranan dergilerde Covid-19 ile ilgili olan makalelerin,

1. Yayımlandı ̆̆g dergiler,

2. Makalelerin yayınlandığ

3. Yazar sayıs1,

4. Konu eğilimi,

5. Örneklem yöntemi,

6. Hedef kitle, 
7. Araştırmanın türü,

8. Araştırmanın modeli,

9. Veri toplama araçları,

10. Veri analiz yöntemleri,

açısından nasıl bir dağılım göstermektedir?

\section{Yöntem}

\section{Araştırmanın Modeli}

Nitel bir araştırma olan bu çalışmada doküman incelemesi yapılmıştır. Doküman incelemesi araştırılmak istenen konu ile ilgili belgelerin analizini içermektedir (Sığrı, 2018, s.248). Araştırmacıya zaman tasarrufu sağlayan doküman analizi "nitel araştırmalarda etkili bir şekilde kullanılması gereken önemli bilgi” kaynakları olup, araştırmacı “gözlem veya görüşme yapmadan” gerekeli bilgiyi edinebilir. Ayrıca bu yöntem tek başına kullanılabileceği gibi “diğer veri toplama yöntemleri ile birlikte de kullanılabilir" (Yıldırım ve Şimşek, 2011, s.187).

\section{Araştırmanın Veri Kaynağı}

Çalışmanın veri kaynağı TR-Dizin resmi internet sayfasında ${ }^{\dagger}$ veri tabanı olarak "sosyal" ve konu alanı olarak ise "eğitim, eğitim araştırmaları" filtrelemeleri sonucunda elde edilmiş olan 140 dergidir ${ }^{\ddagger}$. Salgının ortaya çıkış zamanı göz önünde bulundurularak bu dergilerin sadece 2020 ve 2021 (Nisan ayına kadar) yıllarında yayımlanmış olan sayıları incelenmiş ve içeriğinde “covid-19, pandemi, korona, online, uzaktan eğitim, çevrimiçi”" kelimelerinden biri olan ve verileri 2020-2021 yıllarında elde edilmiş olan 96 makale ile karşılaşılmıştır. Çalışmada sadece araştırma makaleleri incelenmiştir. Bu nedenle 8 adet derleme çalışması, 3 adet çalışma verisi salgın sürecinden önce elde edilmiş olan çalışma, 5 adet eğitim konulu olmayan çalışma, 1 adet görüş bildiren makale ve 2 adet araştırmacılar tarafından yeterli bilgi elde edilemeyen çalışma değerlendirmeye alınmamıştır. Dolayısıyla 19 çalışma araştırma dışında bırakılmış ve çalışmaya 77 makale ile devam edilmiştir. Makaleler yukarıda belirtilmiş olan sorular çerçevesinde değerlendirilmiştir.

\footnotetext{
${ }^{\dagger}$ https://app.trdizin.gov.tr/kabul-dergi-listesi?query=defaultSearchField-AND-*\&query=category.asFacet-AND\%22Sosyal\%22\&query=subject.asFacet-AND-\%22Eğitim,\%20Eğitim\%20Araştırmaları\%22

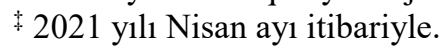




\section{Örnekleme Yöntemi}

Çalışmanın örneklemi, bir araştırma problemini ve çalışmada ele alınan konuyu anlamaya yönelik olarak bilgi alınabilecek veri kaynağının bilinçli bir şekilde araştırmacının kendisi tarafindan belirlendiği (Creswell, 2013, s.156) amaçlı örnekleme yöntemlerinden biri olan ölçüt örneklem yöntemine göre belirlenmiştir. Ölçüt örneklem, araştırmadaki kriter(ler)i karşılayan örnekleri belirlemek için kullanılan örnekleme yöntemidir (Miles ve Huberman, 1994, s.28). Bu çalışmanın ilk ölçütü değerlendirilmeye alınacak olan makalelerin ULAKBİM TR-Dizin tarafından taranan eğitim ile ilgili dergilerde yer almasıdır. Daha sonra makalelerin covid-19, korona, online, uzaktan eğitim, çevrimiçi anahtar kelimelerinden en az birini içermesi, araştırma makalesi olması ve çalışmanın salgın süreci içerisinde başlanıp tamamlanması ölçütleri dikkate alınmıştır.

\section{Veri Toplama Aracı}

Araştırmanın verileri, araştırmacılar tarafından hazırlanan "Makale Değerlendirme Formu" aracılığı ile toplanmıştır. Formun hazırlanması aşamasında eğitim bilimleri alanında uzman olan iki akademisyenin görüşü alınmıştır. Uzmanlardan alınan görüş ve öneriler doğrultusunda forma son hali verilmiştir. Formda; makale numarası, yayın dili, dergi künye bilgileri, yayım yılı, katılımcı üniversite ve diğer kurumların sayıları ve isimleri, yazar sayısı, araştırmanın konusu, örneklem belirleme yöntemi, hedef kitle, araştırmanın türü, araştırma modeli, veri toplama araçları ve şekli, veri toplama aracı sayısı, veri analiz yöntemi bilgilerine yer verilmiştir. İncelenecek makale sayısı kadar form oluşturularak, her bir makaleden elde edilen bilgiler formlara aktarılmıştır.

\section{Verilerin Analizi}

ULAKBİM-TR dizinde taranan ve 2020-2021 yılları arasında eğitim alanında yapılan Covid-19 ile ilgili makalelerin incelendiği bu çalışmada nitel araştırma yöntemlerinden biri olan içerik analizi kullanılmıştır. İçerik analizi "toplanan verileri açıklayabilecek kavramlara ve ilişkilere ulaşmayı amaçlayan bir” yöntemdir. İlkin betimsel analizde özetlenmiş olan veriler içerik analizi ile daha da derinleştirilerek incelenir. İçerik analizi, incelenen dokümanlardan elde edilen verilerin kodlanması, temaların bulunması, kodlama ve temaların organizasyonu, verilerin bu kodlar ve temalara göre değerlendirilmesi ve elde edilen bulguların ortaya konularak yorumlanması bölümlerinden oluşur (Sığrı, 2018, s.280). Bu çalışmada elde edilen 
bilgiler öncelikle araştırmacılar tarafından daha önceden belirlenen ölçütlere göre kodlanmış ve temalar bulunmuştur. $\mathrm{Bu}$ aşamalarda araştırmada ele alınıp incelenecek olan "araştırma makaleleri” değerlendirmeye alınmış bunun dışındaki makaleler araştırma kapsamından çıkartılmış ve daha önceden belirlenmiş olan araştırma soruları kapsamında temalar oluşturulmuştur. Daha sonra bu kodlama ve temalara göre veriler organize edilmiş ve sayısal hale getirilerek değerlendirilerek ve yorumlanmaya çalışılmıştır. Örneklem belirleme yöntemi, hedef kitle, araştırmanın türü, araştırma modeli, veri toplama araçları ve şekli, veri toplama aracı sayısı, veri analiz yöntemi bilgileri incelenirken büyük bir çoğunlukla makale yazarlarının araştırmalarında kullandıkları adlandırmalar kullanılmıştır. Ancak söz gelimi hedef kitleden söz edilirken tüm paydaşların yer aldığı çalışmalarda paydaşlar tek tek yazılmak yerine "paydaşlar" olarak ifade edilmiştir. Benzer bir şekilde, söz gelimi çalışmada hem ölçek hem de açık uçlu sorular kullanılmışsa, veri toplama aracı sayısı iki olarak kodlanmıştır. Araştırmanın konusu ise makaleler dikkatlice incelendikten sonra bu çalışmayı yapan her iki araştırmacı tarafından ayrı ayrı belirlenmiş ve fikir birliğine ulaşıldıktan sonra kodlama yapılmıştır. Elde edilen bulgular frekans ve oranlarıyla tablolar halinde sunulmuştur.

\section{Geçerlik ve Güvenirlik}

Çalışmada elde edilen verilerin geçerliğini ve güvenirliğini sağlamak amacıyla; veri toplama ve analiz süreci ayrıntılı olarak anlatılmış ve ele alınan makaleler araştırmacılar tarafından ayrı ayrı değerlendirilerek veri kayıt formuna işlenmiştir. İncelenen makalelerin kodlayıcılar arası güvenirliğini belirlemek için Miles ve Huberman'1n (1994),

$$
\text { Güvenirlik }=\frac{G \text { örüş birliği sayısı }}{\text { Görüş birliği sayısı }+ \text { Görüş ayrılığı sayısı }}
$$

formülünden yararlanılmıştır. Bu çalışmada incelenen makalelerden 69 tanesinde araştırmacılar tarafından görüş birliğine ulaşılırken sekiz tanesinde görüş birliği sağlanamamıştır. Bu değerlere göre yapılan hesaplama ile güvenirlik değer 0,81 olarak elde edilmiştir. Bu değerin 0,70’in üzerinde olması kodlayıcılar arasında güvenirliğin olduğunu göstermektedir. Görüş ayrılığı olan kodlar araştırmacılar tarafından tartışılarak görüş birliğine ulaşılmıştır.

\section{Bulgular}

Çalışmanın bu bölümünde araştırmanın konusu ile ilgili elde edilen bulgulara yer verilmiştir. Yapılan çalışmada ULAKBİM TR-Dizin tarafından taranan ve Covid-19 salgını konusunun ele alındığı eğitimle ilgili araştırma makalelerin yayımlandığı dergilere göre dağılımı Tablo 1'de belirtildiği gibidir. 
Tablo 1. Makalelerin yayımlandıkları dergilere göre dă̆ılımı

\begin{tabular}{|c|c|c|}
\hline Dergi Adı & Makale Sayısı & Yüzde (\%) \\
\hline Milli Eğitim Dergisi & 36 & 46,8 \\
\hline International Online Journal of Education and Teaching & 7 & 9,1 \\
\hline Turkish Online Journal of Distance Education & 5 & 6,5 \\
\hline Turkish Studies-Educational Science & 5 & 6,5 \\
\hline İlköğretim Online & 3 & 3,9 \\
\hline Educational Science: Theory and Practices & 2 & 2,6 \\
\hline Journal of Qualitative Research in Education & 2 & 2,6 \\
\hline Türk Eğitim Bilimleri Dergisi & 2 & 2,6 \\
\hline Akdeniz Eğitim Araştırmaları Dergisi & 1 & 1,3 \\
\hline Atatürk Üniversitesi Kazım Karabekir Eğitim Fakültesi Dergisi & 1 & 1,3 \\
\hline Eğitimde Nitel Araştırmalar Dergisi & 1 & 1,3 \\
\hline Eurasian Journal of Educational Research & 1 & 1,3 \\
\hline HAYEF Journal of Education & 1 & 1,3 \\
\hline International Journal of Assesment Tools in Education & 1 & 1,3 \\
\hline Journal of Turkish Science Education & 1 & 1,3 \\
\hline Kastamonu Eğitim Dergisi & 1 & 1,3 \\
\hline Kocaeli Üniversitesi Eğitim Fakültesi Dergisi & 1 & 1,3 \\
\hline Mehmet Akif Ersoy Üniversitesi Eğitim Fakültesi Dergisi & 1 & 1,3 \\
\hline Necatibey Eğitim Fakültesi Elektronik Fen ve Matematik Dergisi & 1 & 1,3 \\
\hline Sakarya Üniversitesi Eğitim Fakültesi Dergisi & 1 & 1,3 \\
\hline Yaşadıkça Eğitim & 1 & 1,3 \\
\hline Yükseköğretim Dergisi & 1 & 1,3 \\
\hline Baskent University Journal of Education & 1 & 1,3 \\
\hline TOPLAM & 77 & 100,0 \\
\hline
\end{tabular}

Tablo 1'de verilen değerlerden de görüldüğü gibi Covd-19 salgını konusu ile ilgili en fazla (n=36; \%46,8) yayının yapıldı̆̆ı dergi 2020 yılında "Salgın Sürecinde Türkiye'de ve Dünya'da Eğitim” konulu bir “özel sayı” yayınlayan Milli Eğitim Dergisidir. Bunu International Online Journal of Education and Teaching dergisi izlemektedir ( $\mathrm{n}=7 ; \% 9,1)$. Toplam 15 dergide ise birer yayın yapıldığ görülmektedir. 
YYÜ Eğitim Fakültesi Dergisi (YYU Journal of Education Faculty), 2021;18(2)275-299,http://efdergi.yyu.edu.tr,

Salgının Türkiye'de görüldügü 2020 yılı ve sonrasında yapılan çalışmaların bu yıllara göre dağ 11 ımı Tablo 2'de verilmiştir.

Tablo 2. Makalelerin yayımlandı ̆̆ yıllara göre dă̆ılımları

\begin{tabular}{lrrr}
\hline Yayım Yılı & Makale Sayısı & Yüzde (\%) \\
\hline 2020 & 55 & 71,4 \\
2021 & 22 & 28,6 \\
\hline & TOPLAM & $\mathbf{7 7}$ & $\mathbf{1 0 0 , 0}$
\end{tabular}

Tablo 2 incelendiğinde en fazla makalenin, salgının başlangıcından itibaren yaklaşık dokuz aylık bir zaman dilimini içeren 2020 yılında yapıldığı görülmektedir ( $n=55 ; \% 71,4)$.

Yapılan çalışmada ele alınan bir diğer konu Covid-19 salgını ile ilgili yapılan eğitimle ilgili yayınlardaki yazar sayılarının nasıl bir dağılım gösterdiğidir. Verilerin yazar sayılarına göre dağılımı Tablo 3'de verildiği gibidir.

Tablo 3. Makalelerin yazar sayılarına göre dă̆ılımı

\begin{tabular}{|c|c|c|}
\hline Yazar Sayısı & Makale Sayısı & Yüzde (\%) \\
\hline 1 & 22 & 28,6 \\
\hline 2 & 31 & 40,3 \\
\hline 3 & 14 & 18,2 \\
\hline 4 & 6 & 7,8 \\
\hline 5 & 2 & 2,6 \\
\hline 6 & 2 & 2,6 \\
\hline & 77 & 100,0 \\
\hline
\end{tabular}

Tablo 3'de verilen değerlere göre yapılan çalışmaların çoğunluğunu $(n=55 ; \% 71,4)$ birden fazla yazarlı çalışmalar olduğu görülmektedir. Yayınların çoğunluğunu $(n=31 ; \% 40,3)$ iki yazarlı çalışmalar oluştururken bunu tek yazarlı çalışmalar takip etmektedir ( $\mathrm{n}=22 \% 28,6)$.

Çalışmada Covid-19 salgın sürecinde eğitimle ilgili yapılan makalelerin konu eğilimlerinin ne olduğu belirlenmeye çalışılmış ve yapılan çalışmaların eğilimlerinin ağırlıklı olarak uzaktan eğitime ilişkin görüş ve değerlendirmeler $(n=24$; \%31,2) yönünde olduğu tespit edilmiştir. Konu eğilimleri ile ilgili tüm bulgular Tablo 4'de belirtildiği gibidir.

Tablo 4. Makalelerdeki araştırma konu eğilimlerinin dağılımı

\begin{tabular}{lll}
\hline Araştırma Konusu & Makale Sayısı & Yüzde (\%) \\
\hline
\end{tabular}


Basındaki Haberler

Başarı ve Memnuniyet

Ders Materyali İnceleme

Ders ve Etkinlik Değerlendirme

Dil Eğitimi

Hazır bulunuşluk

Ölçme ve Değerlendirme

Özel Eğitim

Rol ve Yeterlilikler

Tutum, Algı ve Davranışlar

Uzaktan Eğitim Sürecine Uyum ve Karşılaşılan Sorunlar

Uzaktan Eğitim Teknolojisi

Uzaktan Eğitime İlişkin Görüş ve Değerlendirmeler

1

5

1

11

5

4

1

5

1

8

7

1,3

6,5

1,3

14,3

6,5

5,2

1,3

6,5

1,3

10,4

9,1

5,2

TOPLAM

Tablo 4'de verilen değerler incelendiğinde 24 çalışmanın uzaktan eğitime ilişkin görüş ve değerlendirmelere yönelik olduğu, 11 çalışmanın konusunun ise ders ve etkinliklerin değerlendirilmesine yönelik olduğu görülmektedir. Sekiz çalışmanın konusu öğrencilerin, öğretmenlerin uzaktan eğitimle ilgili tutum, algı ve davranışları, yedi çalışmanın konusu ise uzaktan eğitim sürecine uyum ve süreçte yaşanan sorunlara ilişkin konular içermektedir. Beşer çalışmada öğrencilerin ve diğer paydaşların başarı ve memnuniyetleri, uzaktan eğitim ile dil eğitimi ve özel eğitim konuları ele alınmıştır. Dörder çalışmada ise öğretmen ve öğrencilerin hazır bulunuşlukları ile uzaktan eğitim teknolojileri konuları ele alınmıştır. Ayrıca süreç içerisinde eğitimle ilgili olarak basında çıkan haberler, ders materyali değerlendirme, ölçme ve değerlendirme ve öğretmenlerin rol ve yeterlilikleri ile ilgili birer çalışma olduğu görülmektedir.

Çalışmalarda kullanılan örnekleme yöntemlerinin neler olduğunu belirlemek amacıyla sürdürülen analizler sonucunda elde dilen bulgular Tablo 6' da belirtildiği gibidir.

Tablo 5. Örnekleme yöntemiyle ilgili dağllımlar 
Örnekleme Yöntemi

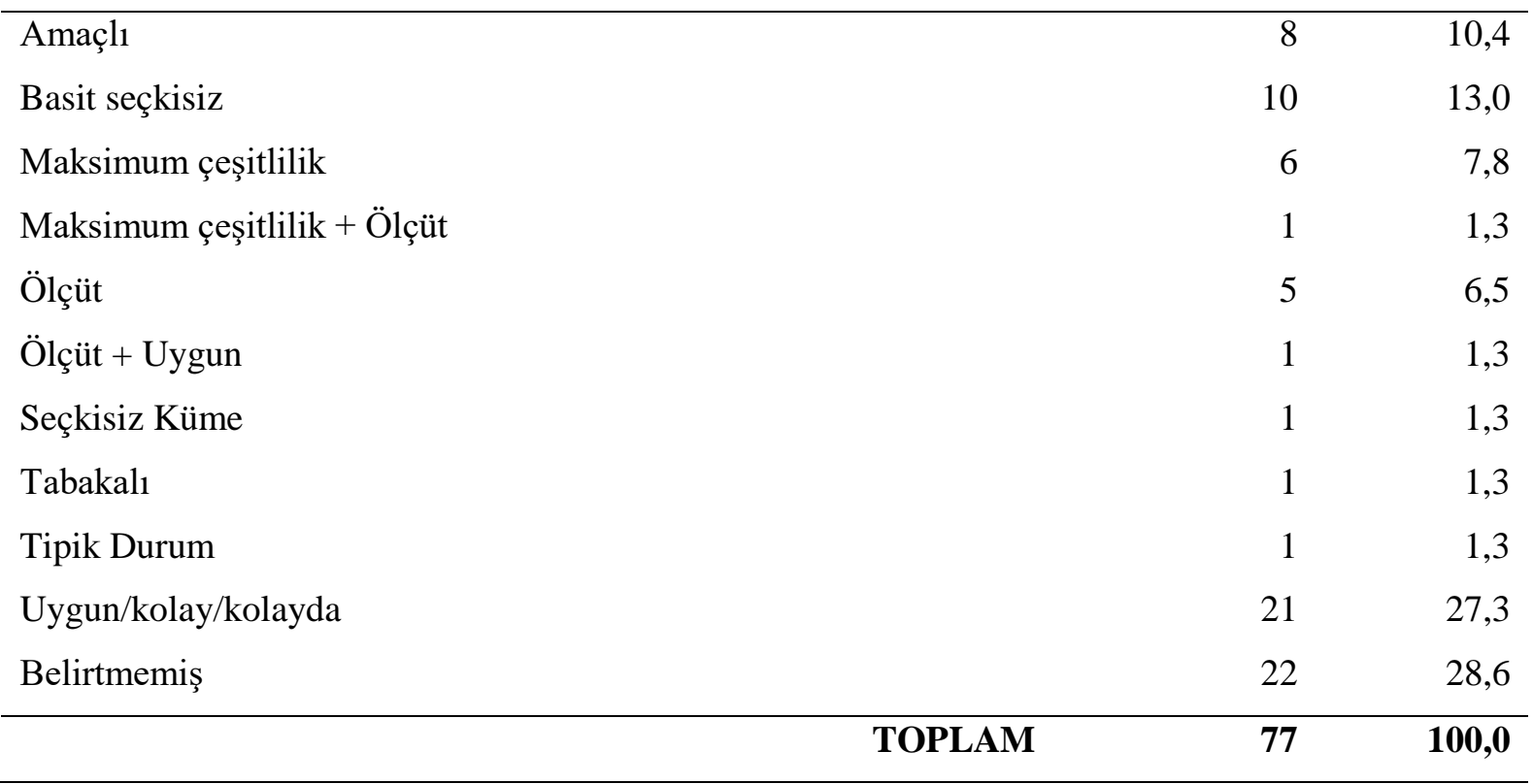

Yapılan çalışmalarda üzerinde çalışılacak olan çalışma gruplarını belirlemek amacıyla kullanılan örnekleme yöntemlerine ilişkin Tablo 5'deki bulgular incelendiğinde 22 (\%28,6) çalışmada örnekleme yöntemi ile ilgili bir bilgiye rastlanmadığı görülmektedir. Bazı çalışmalarda ise birden fazla örnekleme yöntemi kullanılarak çalışmalar yürütülmüştür. İncelenen çalışmalarda en fazla kullanılan örnekleme yöntemi uygun/kolay/kolayda örnekleme yöntemidir ( $\mathrm{n}=21$; \%27,3). Bu yöntemden sonra en fazla kullanılan örnekleme yöntemi basit seçkisiz örneklemedir ( $\mathrm{n}=10 ; \% 13,0)$. Altı çalışma maksimum çeşitlilik $(\% 7,8)$ örnekleme yönteminden yararlanırken, beş çalışmada ölçüt örneklem yöntemi kullanılmıştır.

Yapılan çalışmalarda ulaşılan hedef kitlenin başka bir deyişle çalışma grubunun kimlerden oluştuğunu belirlemek amacıyla elde edilen bilgiler Tablo 6' da verildiği gibidir.

Tablo 6. Hedef kitle (çalışma grubu) ile ilgili dă̆llımlar

\begin{tabular}{lrr}
\hline Hedef Kitle & Makale Sayısı & Yüzde (\%) \\
\hline Ebeveynler & 6 & 7,8 \\
Etkinlikler & 1 & 1,3 \\
Kurslar & 1 & 1,3 \\
Öğrenciler & 32 & 41,6 \\
Öğretim Elemanı+Öğrenci+Yönetici & 1 & 1,3 \\
Öğretim Elemanları & 4 & 5,2 \\
Öğretmen+Öğrenci & 2 & 2,6 \\
Öğretmenler & 17 & 22,1 \\
Öğretmen+Ebeveyn & 2 & 2,6
\end{tabular}


Paydaşlar 2

Üniversiteler

2

Yöneticiler

2

Belirtilmemiş

Tablo 6'da verilen değerlere göre Covid-19 salgını ile ilgili yapılan çalışmaların çoğunluğunun (n=32; \%41,6) öğrenciler ile gerçekleştirildiği görülmektedir. Öğrenciler ile yapılan çalışmaları \%22,1 oranıyla öğretmenler ile yapılan çalışmalar izlemektedir. Bunu ebeveynler ile yürütülen çalışmalar izlemektedir $(n=6 ; \% 7,8)$. Öğretim elemanları ile yürütülen çalışmaların oranı ise \%5,2 olarak belirlenmiştir. Süreç içerisinde bir tane etkinlik izleme, bir tane kurslarla ilgili yapılan ve bir tane de öğretim elemanı, öğrenci ve yöneticilerin birlikte yer aldığı çalışmaya rastlanmıştır. Beş çalışmada hedef kitle hakkında herhangi bir bilgi verilmemiştir.

Yapılan çalışmalarda hangi türden araştırma yöntemlerinin kullanıldığına ilişkin bulgular Tablo 7'de belirtildiği şekilde elde edilmiştir.

Tablo 7. Çalışmalardaki araştırma türleri

\begin{tabular}{|c|c|c|}
\hline Araştırma Türü & Makale Sayısı & Yüzde (\%) \\
\hline Nicel Araştırma & 27 & 35,1 \\
\hline Nitel Araştırma & 38 & 49,4 \\
\hline Nicel + Nitel (Karma) Araştırma & 12 & 15,6 \\
\hline & 77 & 100,0 \\
\hline
\end{tabular}

Ele alınan makalelerdeki araştırma türleri incelendiğinde yapılan çalışmalarda en fazla nitel araştırma yöntemlerinin tercih edildiği görülmektedir $(n=38 ; \% 49,4)$. Nitel araştırmaların ardından tercih edilen yöntem \%35,1'lik oran ile nicel araştırma yöntemleridir ( $n=27)$. Karma araştırma yöntemleri ise araştırmacılar tarafından \%15,6 oranında kullanılmıştır.

Makalelerde kullanılan araştırma modellerinin ne olduğu ile ilgili bulgular Tablo 8'de verildiği şekliyle elde edilmiştir.

Tablo 8. Çalışmalardaki araştırma modellerinin dağılımı

\begin{tabular}{lrr}
\hline Araştırma Modelleri & Makale Sayısı & Yüzde (\%) \\
\hline Betimsel & 6 & 7,8 \\
Durum Çalışması & 17 & 22,1 \\
Görüşme & 4 & 5,2
\end{tabular}


Olgubilim

Tarama

Temel Nitel

Diğer

Belirtilmemiş

Tablo 8'de verilen değerler incelendiğinde yapılan çalışmalarda en fazla tarama modelinin (n=18; \%23,4) ve durum çalışmasının $(\mathrm{n}=17 ; \% 22,1)$ kullanıldı̆̆ 1 görülmektedir. $\mathrm{Bu}$ modelleri takiben sırasıyla betimsel araştırma modelinin $(n=6 ; \% 7,8)$ ve görüşme $(n=4 ; \% 5,2)$, olgubilim $(n=5 ; \% 6,5)$ ve temel nitel $(n=4 ; \% 5,2)$ araştırma modellerinin kullanıldığ belirlenmiştir. Diğer olarak belirtilen araştırma modelleri ise birleştirme (çeşitleme), doküman, dönüştürücü karma, eş zamanlı karma, eylem araştırması, iç içe geçmiş tek durum, keşfedici sıralı karma, meta-etnografi ve yakınsayan desen modelleridir. Bu modellerin her biri birer araştırmada kullanılmışlardır. İncelenen makalelerin 12'sinde ise model belirtilmediği görülmüştür.

Yapılan çalışmalarda kullanılan veri toplama araçları için sürdürülen analizler neticesinde elde edilen bulgular Tablo 9' da verilmiştir.

Tablo 9. Veri toplama araçlarının dağılımı

\begin{tabular}{|c|c|c|}
\hline Veri Toplama Araçları & Makale Sayısı & Yüzde (\%) \\
\hline Anket & 17 & 22,1 \\
\hline Anket + Görüşme Formu & 6 & 7,8 \\
\hline Doküman Formu & 6 & 7,8 \\
\hline Görüşme Formu & 25 & 32,5 \\
\hline Görüşme Formu + Doküman Formu & 4 & 5,2 \\
\hline Ölçek & 11 & 14,3 \\
\hline Ölçek + Görüşme Formu & 2 & 2,6 \\
\hline Diğerleri & 6 & 7,8 \\
\hline & 77 & 100,0 \\
\hline
\end{tabular}

Tablo 9'da verilen değerlerden de anlaşılacağı üzere bu çalışmada ele alınan ve Covid19 salgını döneminde eğitimle ilgili yapılan çalışmalarda veri toplama aracı olarak en fazla görüşme formları kullanılmıştır $(\mathrm{n}=25$; \%32,5). Bu veri toplama araçlarını takiben anket formlarının ( $\mathrm{n}=17 ; \% 22,1)$ ve ölçek formlarının $(\mathrm{n}=11$; \%14,3) kullanıldığı görülmektedir. Hem anket formlarının hem de görüşme formlarının birlikte kullanıldığı makalelerin sayısı $6(\% 7,8)$, 
doküman inceleme formu kullanılan makale sayısının $6(\% 7,8)$, görüşme formu ve doküman inceleme formunun birlikte kullanıldı̆̆ı makale sayısının $4(\% 5,2)$ ve ölçek ve görüşme formunun birlikte kullanıldığı makale sayısının ise $2(\% 2,6)$ olduğu görülmektedir. Bu araçların dışında kullanılan diğer veri toplama araçlarının (birer makalede anket+ölçek formu, ders kitapları, görüntü, görüşme formu + araştırmacının geliştirdiği test, gözlem formu+doküman inceleme formu+açık uçlu sorular ve yansıtıcı yazılardan oluşan veri toplama araçları) sayısı ise $6(\% 7,8)$ olarak belirlenmiştir.

İncelenen makalelerde kullanılan veri analiz yöntemlerine ilişkin sürdürülen analizler sonucunda elde edilen bulgular Tablo 10'da belirtildiği gibi elde edilmiştir.

Tablo 10. Veri analiz yöntemlerinin dă̆ılımı

\begin{tabular}{|c|c|c|}
\hline Veri Analiz Yöntemleri & Makale Sayısı & Yüzde (\%) \\
\hline ANOVA & 14 & 10,2 \\
\hline t testi & 15 & 10,9 \\
\hline Eşleştirilmiş $\mathrm{t}$ testi & 2 & 1,5 \\
\hline Wilcoxon testi & 2 & 1,5 \\
\hline Korelasyon Analizi & 8 & 5,8 \\
\hline Regresyon Analizi & 1 & 0,7 \\
\hline Ki-kare Testi & 3 & 2,2 \\
\hline Faktör Analizi & 10 & 7,3 \\
\hline Betimsel Analiz & 42 & 30,7 \\
\hline İçerik Analizi & 38 & 27,7 \\
\hline Belirtilmemiş & 2 & 1,5 \\
\hline & 137 & 100,0 \\
\hline
\end{tabular}

Tablo 10'da verilen değerlerden de görüldüğü gibi incelenen makalelerde en fazla kullanılan analiz yöntemi betimsel analizdir ( $\mathrm{n}=42 ; \% 30,7)$. Bu yöntemin ardından, en fazla tercih edilen analiz yöntemi içerik analizidir ( $n=38$; \%27,7). Ayrıca 15 çalışmada $t$ testi kullanılırken, 14 çalışmada ise ANOVA yöntemi kullanılarak değerlendirmeler yapılmıştır. Yapılan çalışmaların onunda $(\% 7,3)$ faktör analizi kullanılmış, sekiz $(\% 5,8)$ çalışmada korelasyon analizi, üç $(\% 2,2)$ çalışmada ise ki-kare testinden yararlanılmıştır. Regresyon analizi $(n=1 ; \% 0,7)$, eşleştirilmiş t testi $(n=2 ; \% 1,5)$, Wilcoxon testi $(n=2, \% 1,5)$ testlerinin çok az sayıda kullanıldığı görülmüştür. Bazı çalışmalarda birden fazla analiz yöntemi bir arada kullanıldığı için analiz yöntemlerinin sayısı $(n=137)$ makale sayısından fazladır. 


\section{Tartışma, Sonuç ve Öneriler}

Covid-19 salgını 2020 yılının başından beri tüm dünyanın odağındaki temel konudur. Konunun doğrudan insan sağlığı ile ilgili olması insana ilişkin alanları da derinden etkilemiştir. $\mathrm{Bu}$ alanlardan biri de hiç kuşku yok ki eğitim ve eğitimi ilgilendiren konulardır. Eğitim ile ilgili yapılan akademik çalışmaların da bu konuların başında geldiği söylenebilir.

Bu çalışmada Covid-19 salgını sürecinde ULAKBİM TR-Dizinde taranan eğitimle ilgili dergilerde yayınlanan ve konusunda bu süreci içeren çalışmalar incelenmiştir. Yapılan çalışmaların ağırlıklı olarak Milli Eğitim Dergisinde yer aldığı belirlenmiştir. Bunun temel nedeninin bu derginin 2020 yılında bu sürece ilişkin “Salgın Sürecinde Türkiye'de ve Dünya'da Eğitim” temalı bir özel sayı yayınlamış olduğu söylenebilir. Makalelerin yıllara göre dağımı incelendiğinde en fazla yayının 2020 yılında olduğu görülmektedir. Bunun temel nedeni hastalık ortaya çıtıktan hemen sonra eğitim üzerindeki etkilerinin ne olduğu, eğitimin tüm paydaşları için içinde bulunduğumuz süreç kadar yaygın olmayan, dolayısıyla pek bilindik olmayan ve eğitimin tüm kademelerini doğrudan ilgilendiren uzaktan eğitim sürecinin yansımalarının nasıl olduğunun merak konusu olması düşünülebilir. Diğer bir neden ise 2020 yılına ilişsin değerlendirmeler yaklaşık 9 aylık bir süreyi, 2021 yılına ilişkin değerlendirmelerin ise yaklaşık 3 aylık bir süreyi kapsamasıdır. Zira bu çalışmada makalelerin değerlendirilmesi Nisan ayının başında sonlandırılmıştır.

Makaleler çoğunlukla iki araştırmacı tarafında gerçekleştirilmiş çalışmalardır. Tek yazarlı, iki yazarlı ve üç yazarlı yapılan çalışmalar diğer gruplara göre büyük çoğunluğu oluşturmaktadır. Genellikle birden fazla araştırmacı tarafından yapılan çalışmalarda daha fazla katılımcıya ulaşmanın mümkün olduğu söylenebilir. Özellikle uzaktan eğitim sürecinde katılımcıya ulaşmadaki güçlükler düşünüldüğünde, araştırmacıların derslerinde kullandıkları elektronik ders işleme araçları, sosyal medya platformları ya da kendi öğrencilerine veya diğer katılımcılara ulaşabilme imkanlarının araştırmacı sayısının birden fazla olmasına neden olduğu düşünülebilir. Makale incelemesi konusunda yapılan diğer çalışmalar incelendiğinde benzer sonuçlara rastlamak mümkündür. Söz gelimi, Şara, Karadedeli ve Hasanoğlu (2016) tarafından yapılan "Sınıf Yönetimi”" alanındaki çalışmaların incelenmesinde makalelerin çoğunlukla iki ve daha fazla araştırmacı tarafından gerçekleştirildiği ve yine ağırlıklı olarak iki araştırmacının çoğunlukta olduğu görülmektedir. Öğretmen güçlendirme konusunda Hıdıroğlu ve Tanrı̈ven (2020) tarafından yapılan çalışmada üç yazarlı çalışmaların ağırlıklı olduğunu ve tek, iki ve üç 
yazarlı çalışmaların diğer gruplardan belirgin bir farklılık gösterdiğini belirmektedirler. Benzer bir şekilde Hıdıroğlu (2020) tarafında yapılan eğitim yönetimi ile ilgili çalışmaların; Hatipoğlu, Hıdıroğlu ve Tok (2018) tarafından yapılan ve yine eğitim yönetimi alanındaki çalışmaların; Çiftçi ve Ersoy (2019) tarafında yapılan ve okul öncesi eğitimi ilgili çalışmaların ağırlıklı olarak iki yazarlı çalışmalar olduğu ifade edilmektedir.

İnsan yaşamına giren değişikliklerin insanların farklı görüş ve değerlendirmelerini de birlikte getirdiği söylenebilir. Hiç kuşku yok ki salgın süreci çağımız insanının en büyük tecrübelerinden birini yaşamasına da sahne olmuştur. Yaşanan bu tecrübelerden biri de eğitime ilişkin yeniliklerin rol aldığı yaşantılardır. Yapılan bu çalışmada, çeşitli dergilerde yayımlanmış makalelerin büyük bir çoğunluğunun uzaktan eğitime ilişskin görüş ve değerlendirmelerin çeşitli şekillerde ele alındığı tespit edilmiştir. Zira bu süreç tüm dünyanın bir anda hep birlikte yüz yüze eğitime ara verip uzaktan eğitime geçmesine neden olmuştur. Şüphesiz, yaşanan bu süreç yapılabilecek araştırmalar için yeni problem durumlarını da beraberinde getirmiştir. Zira, “hissedilen ve giderilmek istenen her güçlük potansiyel bir ‘problem’ dir” (Karasar, 2020, s.81). Araştırılacak pek çok problemin olduğunu belirten Karasar, "bunlardan birinin seçilebilmesi için, her şeyden önce onun önemsenmesi ya da belki daha doğrusu 'araştırmacıya çarpması' gerekir”. Bu ise kendiliğinden olan bir süreç olmayıp, araştırmacıların o probleme karşı özel yönelimini, ilgisini, duyarlılı̆̆ını gerektirmektedir (2020, s.82). Araştırmalarda karşılaşılan önemli aşamalardan biri problemin seçimidir (2020, s.83). Salgın sürecinde pek çok alana neredeyse tüm alanlara- ilişkin problemler bir yumak halinde araştırmacıların karşısına çıkmıştır. Bu çalışmada incelenen makalelerden de görüldüğü gibi yaşanan bu süreç karşısında en fazla uzaktan eğitime ilişkin görüş ve değerlendirmelerin nasıl olduğu ilgi çekici olmuştur. Bunun dışında yine ders ve etkinlik değerlendirme, tutum, algı ve davranışlar, sürece ilişkin uyum ve süreçte karşılaşılan sorunlar başta olmak üzere pek çok konu araştırmacıların ilgisini çekmiştir.

Bilimsel bir çalışmanın önemli aşamalarından bir de çalışmanın örneklemidir. Örneklem belirleme ise rastgele bir şey olmayıp üzerinde hassasiyetle durulması gereken bir konudur. Zira çalışmada kullanılan örneklemin evreni temsil yeteneği olmalıdır. Bu nedenle araştırmacıların çalışmalarını yayına hazırlarken kullandıkları örneklem yöntemi hakkında bilgi vermeleri önemlidir. Bu çalışmada, makalelerde örneklemin nasıl belirlendiği incelenirken çalışmaların azımsanamayacak bir bölümünde örneklem belirleme yöntemi ile ilgili herhangi bir bilgiye rastlanamamıştır. Daha önceki çalışmalarda da (Hıdıroğlu ve Tanrıöğen, 2020; Şahin ve Boztunç Öztürk, 2018; Seferoğlu ve Kurtoğlu, 2013) benzer sonuçlara rastlamak 
mümkündür. $\mathrm{Bu}$ çalışmada örnekleme yönteminin belirtildiği çalışmaların büyük bir bölümünde uygun/kolay/kolayda örnekleme yönteminin tercih edildiği belirlenmiştir. Seferoğlu ve Kurtoğlu (2013), bu tür yöntemlerin kullanılmasındaki temel neden çalışma gruplarına kolay ulaşılabilir olmasıdır. Ayrıca salgın sürecinde verilerin elde edildiği gruplardan yüz yüze veri elde etme imkanının çok az olmasından dolayı bu yöntemin tercih edildiği düşünülebilir. İncelenen makalelerde araştırmacıların çoğunlukla tercih ettiği diğer örnekleme yöntemi basit seçkisiz örnekleme yöntemidir. Benzer bir şekilde Hıdıroğlu ve Tanrı̈öğen (2020)'de yapmış oldukları çalışmalarında incelemiş oldukları makalelerde en fazla basit seçkisiz örneklemin kullanıldığını belirmişlerdir.

Bilimsel çalışmaların hedef kitleleri çalışmanın ele aldığı konuya göre değişiklik gösterir. Bu çalışmada araştırmacıların çoğunlukla, salgın süreci ile ilgili olarak, öğretmen ve öğrencilerin görüşlerini ele alan çalışmalar yaptığı görülmektedir. Bunun nedenin öğretmen ve öğrencilerin eğitimin temel iki unsuru olması olarak değerlendirilebilir. Dolayısıyla uzaktan eğitim sürecinin de olumlu ve olumsuz tüm etkilerinin ilk yansımalarının bu iki temel unsur üzerindeki etkilerinin incelenmesinin önem arz ettiği söylenebilir. Salgın öncesinde, eğitimin farklı konuları ile ilgili olarak yapılan makale inceleme çalışmaları irdelendiğinde (Şara ve diğ., 2016; Doğan ve Tok, 2018; Hatipoğlu, Hıdıroğlu ve Tok, 2018; Hıdıroğlu ve Tanrı̈ŏğen, 2020) çalışmalardaki hedef kitlelerin ağırlıklı olarak öğretmen veya öğrenciler olduğu görülmektedir.

$\mathrm{Bu}$ çalışmalarda incelenen makalelerini çoğunluğunun nitel araştırma türünde olduğu belirlenmiştir. Karma araştıra deseni ise en az tercih edilen araştırma yöntemi olarak belirlenmiştir. Eğitimin farklı alanlarıyla ilgili yapılan diğer çalışmalar (Seferoğlu ve Kurtoğlu, 2013; Doğan ve Tok, 2018; Hatipoğlu ve diğ., 2018; Ersoy ve Çifçi, 2019; Hıdıroğlu ve Tanrı̈ğgen, 2020) incelendiğinde araştırmacıların daha çok nicel araştırma yöntemlerini tercih ettikleri görülmektedir. Buna karşın Hıdıroğlu (2020) eğitim denetimi alanında yürütülen çalışmalarda çoğunlukla nitel araştırma yönteminin kullanıldığını belirtmiştir. Hiç beklenmedik bir şekilde insan yaşamına giren Covid-19 salgınının eğitim üzerindeki etkilerinin ne olduğu ve yine hızla yaşamımıza girmiş olan uzaktan eğitimin etkilerinin ne olduğunun da detaylı bir şekilde ortaya konulması gerektiği söylenebilir. Zira Ekiz’e göre, nitel araştırmalar daha derinlemesine ve doğal ortamında araştırma yapabilme olanağına sahiptir (Aktaran: Doğan ve Tok, 2018).

Makalelerde en fazla kullanılan araştırma modeli tarama modelidir. Araştırmalarda çoğunlukla bu araştırma modelinin tercih edilmesinin temel nedeninin mevcut durumu kendi 
koşulları içinde, olduğu gibi değerlendirmek olduğu söylenebilir. Zira Karasar'a göre, bu modelde "araştırmaya konu olan olay, birey ya da nesne, kendi koşulları içinde ve olduğu gibi tanımlanmaya çalış1lır” (Karasar, 2020, s.109). Bu çalışmada benzer bir şekilde durum çalışmasının da sıklıkla tercih edilmiş bir model olduğu belirlenmiştir. Seferoğlu ve Kurtoğlu (2013) da yaptıkları çalışma ile incelemiş oldukları makalelerde tarama ve durum çalışması modellerinin çoğunlukla kullanılan modeller olduğunu belirtmektedirler. Hıdıroğlu ve Tanrığen, çalışmalarında en sık karşılaşılan modelin tarama modellerinden biri olan ilişki tarama modeli olduğunu belirtmektedirler (Hıdıroğlu ve Tanrıöğen, 2020).

İncelenen makalelerde araştırmacıların yapmış oldukları çalışmalarda ağırlıklı veri toplama aracı olarak görüşme formu, anketler ya da ölçekleri kullandıkları belirlenmiştir. Bazı çalışmalarda ise bu araçlar birlikte kullanılarak çalışmaların verileri elde edilmiştir. Özellikle salgın sürecinin ve uzaktan eğitimin koşulları göz önüne alındığında, hem hızlı olması, katılımcının fazla zamanını almaması, ekonomik olması, özellikle bilgisayar ortamından ve sosyal medya araçları vasıtasıyla katılımcıya ulaştırılmasının kolay olması gibi etkenlerden dolayı, salgın sürecindeki eğitimle ilgili çalışmalarda bu veri toplama araçlarının tercih edildiği veya çalışmaların bu türden araçlar da dikkate alınarak planlandığı düşünülebilir. Salgın öncesinde yapılan makale inceleme çalışmalarda da benzer çalışmaları görmek mümkündür. Söz gelimi Seferoğlu ve Kurtoğlu (2013) inceledikleri çalışmalarda çoğunlukla anketlerin kullanıldığını; Hatipoğlu ve diğ. (2018) anket/ölçek kullanıldığını; Tok ve Doğan (2018) anket/ölçek kullanıldığını; Çifçi ve Ersoy (2019) görüşme formlarının kullanıldığını; Hıdıroğlu ve Tanrığen (2020) ölçek/anket kullanıldığını; Hıdıroğlu (2020) görüşme formlarının kullanıldığını belirtmişlerdir. Elde edilen verilerin analizinde ise çoğunluk betimsel analiz ve içerik analizinden yararlanıldığı belirlenmiştir.

Çalışmada dikkat çekici hususlardan biri de, bazı çalışmalarda örneklem yönteminin, hedef kitlenin, araştırmanın modelinin, veri analiz yönteminin ne olduğunun araştırmacılar tarafından belirtilmemiş olmasıdır. Bu duruma benzer çalışmalarda da rastlamak mümkündür. Söz gelimi, Seferoğlu ve Kurtoğlu (2013)'in yaptıkları çalışmada bazı makalelerde çalışma grubu; Hıdıroğlu ve Tanrıöğen (2020) çalışmalara dahil edilen gruplar hakkında bilgi verilmediğini belirtmektedirler.

Yapılan bu çalışma salgın sürecinin başlangıcından itibaren yaklaşık 13 aylık bir süreci kapsamaktadır. Özellikle salgının etkisinin azalması ile birlikte bu konu ile ilgili çalışmalarında 
artacağı düşünülmektedir. Bu bağlamda, yapılan bu çalışmadan elde edilen bulgular 1şığında şu öneriler dile getirilebilir:

- Bu çalışmanın veri toplama süreci Nisan 2021'de sonlandırılmıştır; dolayısıyla bu tarihten sonraki süreci de kapsayan bu türden çalışmalar ile süreç içerisinde konu eğilimlerinin herhangi bir değişim gösterip göstermediği ya da çalışma konularının nasıl bir eğilim gösterdiği belirlenebilir.

- Bu türden çalışmalar ağırlıklı olarak yöntem kısımlarına ait bilgileri içermektedir. Bu nedenle yapılan çalışmaların yöntem kısmında yer alması gereken bilgilerin açık seçik olarak yazılmasının, başka araştırmacılar için, daha yararlı olacağı söylenebilir.

- Salgın sürecinden sonra görüş ve değerlendirmelerin dışında farklı konulara da ağırlık verilerek farklı çalışmalar yürütülebilir.

- Uygun (kolay ya da kolayda) örneklemin dışında araştırmacılar farklı örneklem yöntemleri kullanarak ulaşılabilecek daha fazla sayıda bireye ulaşarak çalışmalar yürütülebilir.

- Çalışma gruplarının başka bir değişle hedef kitlenin çeşitliliği sağlanarak salgının tüm eğitim paydaşları üzerindeki etkileri daha geniş bir şekilde ele alınarak incelenebilir.

- Çalışmalarda özellikle nitel ve nicel araştırmaların birlikte yürütüldüğü karma araştırma modelleri de kullanılarak ele alınan konular hem nicelik hem de nitelik bakımından değerlendirilebilir.

- Beklenmedik koşullar karşısında uzaktan eğitimin daha etkili bir şekilde yürütülebilmesi için nelerin yapılması gerektiğine ilişkin çalışmalar yürütülebilir. İnsan yaşamı belirsizlikler ile doludur. Ancak her koşulda eğitimin sürdürülmesinin gerekliliği de kaçınılmazdır. Bu nedenle sadece salgın değil farklı senaryolar için de uzaktan eğitim uygulamalarına yönelik çalışmalar planlanabilir; bu yönde sürekli olarak hizmet içi eğitim etkinlikleri düzenlenebilir. Özellikle salgın sürecinden sonra, eğitimin her alanında ani olarak karşılaşılabilecek durumlarda, eğitimin sürdürülebilirliği konusunda yapılacak çalışmaların önemli katkılar sağlayacağı söylenebilir.

\section{Makalenin Bilimdeki Konumu (Yeri)}

Eğitim Bilimleri / Eğitimde Ölçme ve Değerlendirme alanları

\section{Makalenin Bilimdeki Özgünlüğü}


YYÜ Eğitim Fakültesi Dergisi (YYU Journal of Education Faculty), 2021;18(2)275-299,http://efdergi.yyu.edu.tr,

Olağanüstü koşulların söz konusu olduğu Covid-19 salgını sürecinde başta sağlık olmak üzere pek çok alanda çeşitli çalışmalar yapılmaktadır. Bu çalışmada söz konusu bu süreç içerisinde eğitim ile ilgili yapılmış olan araştırmaların bir incelemesi yapılarak yapılan çalışmalar hakkında çeşitli bilgiler ortaya konulmaya çalışılmıştır. Eğitimde, salgın sürecinden önce, makale inceleme çalışmalarına rastlanmasına rağmen salgın döneminde yapılan bu çalışmanın alana ayrıca katkı sağlayacağı düşünülmektedir.

\section{Kaynaklar}

Alemdağ, S. (2018). “Spor Bilimleri Alanıyla İlgili Bilimsel Dergilerde Yayınlanan Makalelerin İncelenmesi”, Atatürk Üniversitesi Beden Eğitimi ve Spor Bilimleri Dergisi, 20(3), 24-31.

Creswell, J.W. (2013). Qualitative inquiry and research design : choosing among five approaches.(2013), Calofornia: SAGE Publication.

Üstün, Ç, ve Özçiftçi, S. (2020). “COVID-19 Pandemisinin Sosyal Yaşam ve Etik Düzlem Üzerine Etkileri: Bir Değerlendirme Çalışması”, Anadolu Kliniği Tıp Bilimleri Dergisi, Ocak 2020; Cilt 25, Özel Sayı 1, 142-153.

Çifçi, M, ve Ersoy, M. (2019). “Okulöncesi eğitimi alanındaki araştırmaların yönelimleri: Bir içerik analizi”, Cumhuriyet International Journal of Education, 8(3), 862-886. http://dx.doi.org/10.30703/cije.581302

Doğan, H. ve Tok, T. N. (2018). “Türkiye’de eğitim bilimleri alanında yayınlanan makalelerin incelenmesi: Eğitim ve Bilim Dergisi Örneği”, Curr Res Educ, 4(2), 94-109. 
YYÜ Eğitim Fakültesi Dergisi (YYU Journal of Education Faculty), 2021;18(2)275-299,http://efdergi.yyu.edu.tr,

Hatipoğlu, G, Hıdıroğlu Özkan Y, ve Tok T.N. (2018). “Türkiye'de Eğitim Yönetimi Alanındaki makalelere yönelik bir içerik analizi”, Journal of Human Science, 15(2), 1362-1380. Doi:10.14687/jhs.v15i2.5165

Hıdıroğlu Özkan, Y. (2020). “Türkiye’de Eğitim Denetimi Alanında Yayımlanan Makalelerin İncelenmesi”, Batı Anadolu Ĕgitim Bilimleri Dergisi, 11 (1), 1-22.

Hıdıroğlu, Özkan Y, Tanröğen, A. (2020). “Öğretmen Güçlendirmeyle İlgili Araştırmaların Tematik, Metodolojik ve İstatistiksel Olarak İncelenmesi”, İnönü Üniversitesi Eğitim Fakültesi Dergisi Cilt 21, Say1 2, 2020, ss. 616-635.

Karasar, N. (2020). Bilimsel Araştırma Yöntemi: Kavramlar Illkeler Teknikler, Ankara: Nobel Akademi Yayıncılık.

Kurtoğlu, M, Seferoğlu, S.S. (2013). “Öğretmenlerin Teknoloji Kullanımı ile İlgili Türkiye Kaynaklı Dergilerde Yayımlanmış Makalelerin İncelenmesi”, Journal of Instructional Technologies \& Teacher Education, 2(3), 1-10.

Miles, M.B, Huberman, M.A. (1994). Qualitative Data Analysis: An Expanded Sourcebook, California: SAGE Publication.

Sığrı, Ü. (2018). Nitel Araştırma Yöntemleri. İstanbul: Beta Yayıncılık.

Şara, P, Karadedeli, İ, ve Hasanoğlu, G. (2016). “Sınıf Yönetimi Alanında Ulakbim’de Taranan Makalelerin İncelenmesi”, Kırlkkale Üniversitesi Sosyal Bilimler Dergisi, 6(2).

Yıldırım, A, Şimşek, H. (2011). Sosyal Bilimlerde Nitel Araştırma Yöntemleri, Ankara: Seçkin Yayınc1lik. 


\section{Summary}

\section{Statement of The Problem}

Scientific articles, which have a great importance and place in sharing and dissemination of scientific findings, offer researchers ample opportunities to conduct such studies. As a research subject, it is often possible to come across the examination of scientific studies on any subject. Because these studies, on the one hand, provide information about the nature of the studies on the subject (Seferoğlu ve Kurtoğlu, 2013, p.1)and the studies carried out in the field, on the other hand, they are important in terms of giving tidy information to other researchers. The World had to face the danger of an epidemic that started in Wuhan, China's Hubei province, in December 2019. The World has been struggling with a deadly virus, which has been defined as SARS-CoV-2 for over a year and whose clinical picture is named as Coronovirus disease COVID-19 (Üstün and Özçiftçi, 2020, p. 143). The Covid-19 outbreak has affected human life as well as studies in various fields of science. One of these areas is undoubtedly education. Considering that the studies in the field of education are mostly related to the stakeholders of education and that the majority of the studies are carried out in the field, it can be thought that the epidemic process will also be reflected in the studies to be carried out on education.

\section{Aim of The Study}

The aim of this study is not the quality or quantity of the studies carried out during this process, but to obtain information about the subject and methodological orientations and the studies on Covid-19 in the field of education during the epidemic period. For this, answers to the following questions were sought:

What distribution do the articles related to Covid-19 and published in the journals scanned in the ULAKBIM TR-Index show in terms of the journals in which the articles were published, the year the articles were published, the number of authors, the trend of the subject, the sampling method, the target audience, the type of the research, the research model, the data collection tools and the data analysis methods?

\section{Method}

The study is a qualitative research, and document analysis was carried out in the study. Within the scope of this study, articles about Covid-19 in the field of education were examined and data on research questions were collected. The data of the study is 140 journals related to education on the TR-Index official website. Since only research articles were examined in the 
study, 77 articles were evaluated. The criterion sampling method was used as the sampling method. Content analysis was used in the analysis of the data.

\section{Findings and Discussion}

It has been determined that the studies are mainly included in the National Education Journal, which published a special issue with the theme "Education in Turkey and the World During the Epidemic Process" during the epidemic process. When the distribution of articles by years is examined, it is seen that the most publications are in 2020. Articles are carried out by two researchers. It has been determined that in most of the articles published in various journals, views and evaluations on distance education are handled in various ways.

It was determined that the convenient/easy/convenience sampling method was preferred in most of the studies in which the sampling method was specified. It has been determined that the researchers mostly conducted studies dealing with the views of teachers and students regarding the epidemic process. It was determined that the majority of the articles examined in these studies were in the qualitative research type. Mixed research design was determined as the least preferred research method. The most commonly used research model is the survey model. In the articles, it was determined that the researchers mostly used the interview form as a data collection tool in their studies. One of the remarkable points in the study is that in some studies, the sampling method, target audience, research model and data analysis method were not specified by the researchers.

\section{Results and Suggestions}

This study covers a period of approximately 13 months from the beginning of the epidemic process. It is thought that studies on this subject will increase, especially with the decrease of the effect of the epidemic. Some of the suggestions that can be made in the light of the findings obtained as a result of the study are as follows.

* The data collection process for this study was terminated in April 2021; therefore, with such studies covering the period after this date, it can be determined whether the subject trends have changed in the process or what kind of a trend the study subjects have shown.

* Studies can be carried out on what needs to be done in order to carry out distance education more effectively. Human life is full of uncertainties. However, the necessity of continuing education is inevitable under all circumstances. For this reason, studies on distance 
education applications can be planned not only for epidemics but also for different scenarios; In this direction, continuous in-service training activities can be organized. 